\title{
ANÁLISE SOBRE A EFICÁCIA DA OPERAÇÃO URBANA CONSORCIADA E DA OUTORGA ONEROSA DO DIREITO DE CONSTRUIR PARA O DESENVOLVIMENTO DE PERIFERIAS INTRAMUNICIPAIS ${ }^{1}$
}

\author{
ANALYSIS ON THE EFFECTIVENESS OF THE URBAN CONSORTIUM OPERATION AND ONEROUS GRANT OF THE RIGHT \\ TO BUILD FOR THE DEVELOPMENT OF INTRAMUNICIPAL PERIPHERIES
}

\section{RESUMO}

O objetivo deste artigo é compreender em que medida a condição periférica de certas áreas intramunicipais pode comprometer a capacidade de instrumentos de política urbana de gerarem os efeitos que deles são esperados nessas áreas. Por meio de investigação bibliográfica e de coleta de dados, foram analisados os instrumentos da operação urbana consorciada e da outorga onerosa do direito de construir, observando, em particular, as experiências com ambos os instrumentos nos municípios do Rio de Janeiro e de São Paulo. Com base na matriz de produção social do espaço e em uma abordagem institucionalista, a análise realizada evidenciou que os instrumentos investigados, particularmente o caso das operações urbanas consorciadas, deparam-se com limitações institucionais, no espaço urbano, capazes de comprometer sua viabilidade como importantes alternativas de indução do desenvolvimento urbano em grandes periferias intramunicipais. Foi possível constatar que remanescem como desafios comuns, para a eficácia desses instrumentos, o aumento de controle social, a necessidade de redesenho institucional voltado à ampliação de capacidades políticas e redistributivas, assim como a maior projeção das periferias urbanas como categoria de análise institucional.

Palavras-chave: Direito Urbanístico. Desenvolvimento urbano. Política urbana. Periferia urbana. Cidades.

\begin{abstract}
The purpose of this study is to understand to what extent the peripheral condition of certain urban areas circumscribed to large cities may jeopardize the ability of some of the urban policy instruments to generate the effects expected of them in those areas. Through a bibliographical research and secondary data collection, the instruments of the urban consortium operation and the onerous granting of the right to build were analyzed, observing the experiences with both instruments in the municipalities of Rio de Janeiro and São Paulo. Considering the matrix of social production of space and an institutionalist economic approach, the analysis revealed that these instruments face structural socioeconomic constraints in urban space, which can compromise their viability as relevant alternatives for inducing urban development in large urban peripheral regions. Also, some common challenges remain for the effectiveness of these instruments, such as an increased social control, the need for institutional redesign aimed at expanding redistributive capacities, and a greater projection of urban peripheries as a category of institutional analysis.
\end{abstract}

Keywords: Urban Law. Urban Development. Urban Policy. Urban Periphery. Cities.

\section{Carlos Eduardo de Souza Cruz}

${ }^{\text {a }}$ Universidade do Estado do Rio de Janeiro (UERJ), Rio de Janeiro, RJ, Brasil

DOI: $10.12957 /$ geouerj.2020.47273

Correpondência: carloseduardosc@gmail.com

Recebido em: 15 set. 2019

Revisado em: 24 out. 2019

Aceito em: $13 \mathrm{dez} .2019$

\footnotetext{
${ }^{1}$ Em sua maior parte, este artigo constitui síntese de argumentos e de conclusões da dissertação intitulada "Desenvolvimento e Periferia: análise sobre possibilidades de eficácia de instrumentos de política urbana em periferias intramunicipais", que foi apresentada ao Programa de Pós-Graduação em Direito da Faculdade de Direito da Universidade do Estado do Rio de Janeiro em
} 2019. 


\section{INTRODUÇÃO}

Este artigo trata sobre o desenvolvimento de periferias urbanas, à luz das especificidades apresentadas por certas áreas intramunicipais no contexto institucional em que se inserem ${ }^{2}$. Daí a necessidade de investigar o campo relativo às políticas públicas urbanas, o que, no Brasil, pressupõe considerar a importância das formas de atuação dos entes municipais, baseadas, em grande medida, em institutos jurídico-urbanísticos que ainda geram significativos questionamentos a seu respeito. Realizada de acordo com a matriz de produção social do espaço e a partir de uma abordagem institucionalista, esta análise, de base interdisciplinar, objetiva compreender em que medida a condição periférica de certas regiões, circunscritas ao território de grandes municípios, pode comprometer a capacidade de instrumentos de política urbana de gerarem os efeitos que deles são esperados nessas áreas.

Por meio de pesquisa exploratória bibliográfica, bem como de coleta de dados secundários, foram investigadas limitações sistêmicas que afetam a eficácia da operação urbana consorciada e da outorga onerosa do direito de construir nessas áreas. Ambos os instrumentos foram selecionados por serem sensíveis à dinâmica socioeconômica e política subjacente à interação centro-periferia, no espaço urbano, e simultaneamente por consistirem em instrumentos urbanísticos que se valem da concessão de direito adicional construtivo mediante prestação de contrapartida por seus beneficiários.

Este artigo está estruturado em cinco etapas, sendo a primeira esta introdução. Na segunda etapa, procurou-se compreender as relações entre a questão urbana e a questão periférica no Brasil, destacando o tipo de urbanização prevalecente no país, o debate sobre a interação entre centro e periferia urbana, bem como seus desdobramentos sobre a organização espacial das atividades socioeconômicas nas cidades. Na terceira, a análise voltou-se para o desenvolvimento urbano, sendo destacado o estabelecimento do ordenamento jurídico-urbanístico brasileiro e o impacto de aspectos institucionais sobre sua efetividade e sua eficácia. Na quarta etapa, o desenvolvimento urbano periférico é investigado à luz de instrumentos de política urbana, em particular os casos da operação urbana consorciada e da outorga onerosa do direito de construir. A quinta e última etapa é dedicada às considerações finais.

\section{Questão urbana como questão periférica}

\footnotetext{
20 conceito de periferia intramunicipal adotado refere-se às áreas urbanas de maior vulnerabilidade social relativa, circunscritas ao território de grandes municípios, que não estejam localizadas em regiões de maior dinamismo econômico e concentração de riqueza, nem se constituam como vetores prioritários de expansão do mercado imobiliário ou estejam adjacentes a áreas centrais. A utilização desse corte metodológico explica-se: 1. pela necessidade de afastar a investigação sobre periferias urbanas de suas relações com o fenômeno metropolitano; 2. por simplificar a análise das interações centro-periferia em território administrado por apenas um ente municipal; 3. por permitir a investigação das especificidades de desenvolvimento periférico, em municípios de grande extensão territorial e com capacidade político-administrativa para aplicar os instrumentos de política urbana do Estatuto da Cidade.
} 
Entendida como a problemática da reprodução social relacionada ao processo de formação das cidades, a questão urbana tornou-se objeto de grandes preocupações na segunda metade do século passado, conjuntura em que as consequências socioambientais do período de expansão econômica e industrial do pósguerra tornavam-se alarmantes. A escola francesa de sociologia urbana, por exemplo, que teve ampla disseminação no Brasil, desenvolveu análise crítica sobre a urbanização do período de formação da grande cidade industrial do pós-guerra, uma urbanização que foi concebida, de modo geral, como produto de relações sociais, em quadro marcado por contradições classistas, as quais foram associadas ao sistema econômico capitalista; naquele contexto, as reflexões sobre a questão urbana passaram a conceber o espaço urbano como lócus do processo de acumulação do capital e de reprodução da força de trabalho (LOJKINE, 1981; CASTELLS, 1983).

Dadas as especificidades do tipo de urbanização prevalecente no Brasil, pretende-se apresentar uma perspectiva que aproxima a questão urbana brasileira a uma questão periférica, de tal maneira que seja possível evidenciar o fato de que, no país, a problemática da reprodução social relacionada ao processo de urbanização encontra-se indissociável das condições de vulnerabilidade social que marcam a experiência de vida nas periferias das grandes cidades do país. Afinal, a intensa urbanização, ocorrida em contexto que não favorecia a efetividade nem a eficácia da atividade urbanística estatal, função pública por excelência, foi determinante para a configuração de um padrão de ocupação e de reprodução social, nas grandes cidades, que, ainda hoje, submete importante parcela da população mais pobre a condições de significativa vulnerabilidade.

Urbanização periférica no Brasil e a concentração espacial da situação de vulnerabilidade social urbana

Até as primeiras décadas do século $X X$, o crescimento das cidades foi dificultado, no Brasil, pela proeminência de interesses associados ao domínio rural, que limitaram a industrialização do território, suporte material do processo de intensa urbanização que o país experimentaria, notadamente após os compromissos assumidos com a Revolução de 1930. A consolidação do complexo social da industrialização (SANTOS, M., 1993) pressupôs significativas mudanças sociais, que passaram a compreender a prevalência de interesses voltados à modernização conservadora do território, aspecto responsável por gerar dinâmicas concentradoras da rede urbana e sua consequente metropolização (BECKER E EGLER, 1993). Durante a segunda metade do século passado, a "industrialização dos baixos salários" (MARICATO, 1996) exacerbaria a 
arquitetura da desigualdade nas cidades brasileiras, consistente em abrangente quadro de exclusão e de segregação socioespaciais ${ }^{3}$.

Essas circunstâncias têm significativas conexões com o paradigma da urbanização periférica (HOLSTON, 2013), marca da formação da metrópole paulista e, não menos, das grandes cidades do país. Tal paradigma evidencia a sujeição dos mais pobres, no processo de expansão das cidades, especialmente à tríade da vulnerabilidade urbana representada pelos problemas de mobilidade, violência e de moradia precária, tríade que qualifica a natureza do acesso à terra urbana desvalorizada, isto é, a terra periférica.

Em seu estudo, James Holston (2013) analisa a maneira pela qual a expansão da maior cidade do país compreendeu tendências que relegaram as áreas periféricas, aos mais pobres, e as áreas centrais, à população com maior poder aquisitivo. Em verdade, essa constatação constitui a base da atitude, arraigada no meio social, que identifica os conceitos de periferia e de pobreza. Essa identificação evidencia um significativo diferencial entre o processo de periferização, que ocorreu nos principais centros urbanos brasileiros, e o processo de suburbanização, que foi verificado, por exemplo, em cidades norte-americanas. Com efeito, a periferização pode ser compreendida como o processo de expansão das cidades com base em cíclicos assentamentos periféricos, geralmente em loteamentos ilegais e por parte da população de baixa renda, no contexto capitalista de competição por localizações nas cidades (SANTOS, POLIDORI et al, 2017); em contraste, a suburbanização apresentou características bastante contrastantes, estando vinculada, por exemplo, a um ideário modernizador e às classes médias (HALL, 2014).

O paradigma da urbanização periférica evidencia a existência de óbices para que as áreas mais valorizadas da capital paulista, notadamente sua região central, pudessem servir como local de moradia para o grande êxodo que se direcionou à cidade de São Paulo, sobretudo entre as décadas de 1940 e de 1980 . Daí a constatação feita por Holston (2013) acerca do padrão centrífugo de ocupação que prevaleceu naquela cidade, pois, de forma sucessiva, áreas cada vez mais distantes daquelas de maior valorização imobiliária foram ocupadas pela população migrante. Diante de um sistema que comercializa a terra urbana como mais uma mercadoria, os migrantes de baixa renda foram expostos a uma contínua valorização imobiliária que acompanhou as ondas de migração e de assentamento, significando uma cíclica pressão pela periferização que foi levada a cabo sempre pela última leva de migrantes, os quais, sobretudo pelo critério da renda disponível, se viam impossibilitados de estabelecerem-se nos círculos de ocupação mais antigos e mais próximos à região central da cidade.

\footnotetext{
${ }^{3}$ Atenta à origem estrutural dessas condições, Ermínia Maricato (1996, p. 14-15) refere-se à etapa de modernização do território brasileiro como uma "modernização com exclusão", em que a industrialização se processou como "desenvolvimento moderno do atraso".
} 
Essas condições foram agravadas pela incapacidade estatal de colocar em prática políticas habitacionais eficazes e inclusivas que pudessem contemplar meios alternativos de acesso à moradia por parte da população de baixa renda, em áreas bem localizadas e materialmente assistidas, e atenuar o impacto da renda fundiária urbana sobre a precificação do solo nesse processo também. Excluída das áreas centrais, restou à população migrante de baixa renda direcionar-se ciclicamente para, cada vez mais, longínquos assentamentos periféricos, valendo-se de diferentes meios para estabelecerem-se em áreas materialmente desassistidas, as quais viriam a ser objeto de crescente estigma social. Invasões de terras constituíram prática comum no processo de periferização, mas os assentamentos em loteamentos ilegais, sob agência de especuladores e de incorporadores imobiliários, marcaram, em definitivo, o período, ao lado do recurso à autoconstrução ${ }^{4}$.

\section{O dualismo centro-periferia e uma discussão sobre centralidades}

O fim dos anos dourados do capitalismo do pós-guerra ensejou duas tendências de reformas que seriam consolidadas até os anos de 1990: de um lado, a superação do keynesianismo e do Estado de bem-estar pelo ideário neoliberal; de outro, a substituição do modelo fordista de produção pelo pós-fordismo. Nos países desenvolvidos, em especial, políticas comerciais protecionistas passaram a ser suplantadas pelo incentivo às inovações tecnológicas como meio de gerar competitividade comercial e aumento da lucratividade. Essa nova dinâmica, bastante fundada na recuperação da tese schumpeteriana da "destruição criadora" do capitalismo, contrastou-se com as estruturas estáticas do modelo fordista de produção, tendo sido responsável, em grande medida, pela consolidação da chamada "terceira revolução industrial" - ou revolução tecnológica -, em que os avanços da robótica e da ciência da informação têm tido significativo destaque.

A configuração do caráter extensivo da urbanização contemporânea tem a ver com essa nova dinâmica. Em tal contexto, a influência da vida urbana torna-se muito mais abrangente do que no passado. O impacto do avanço tecnológico e o novo dinamismo dos setores primário e terciário conferiram força inédita às redes urbanas, relativizando, muito claramente, a importância de contiguidades territoriais e a própria compreensão daquilo que efetivamente é tido como urbano ou rural. A chamada "urbanização extensiva", expressão da urbanização contemporânea, pressupõe a superação de dicotomias inflexíveis no que se refere à temática urbana, como aquela que se refere à tradicional oposição entre cidade e campo (MONTE-MÓR, 1994, 2006).

\footnotetext{
${ }^{4}$ A atuação desses agentes evidencia que o processo de periferização não ocorreu de maneira inteiramente orgânica, isto é, em grande medida, ele foi induzido, o que estava em consonância com ações e com interesses governamentais, como evidenciam as políticas de remoções (VILLAÇA, 2004). As precárias condições desse espaço demonstram o desamparo do poder público e o descumprimento de obrigações por promotores imobiliários; nessas circunstâncias, a autoconstrução tornou-se importante característica do assentamento periférico, tendo sido realizada em condições deficientes do ponto de vista urbanístico.
} 
Se a explosão da cidade industrial pode ser entendida como o processo de alastramento do tecido urbano pelo território, por outro lado, sua implosão pressupõe a reinvenção dos próprios centros, em dinâmica que reafirma atributos da vida urbana, mas também reconfigura centralidades, hierarquias e comandos em um espaço que se pretende globalmente urbanizado. A preocupação de Henri Lefebvre (1999), em relação a essas transformações, está no fato de que o processo retratado não elimina, por si, a divisão socioespacial da cidade industrial, que se tornara muito evidente nos anos de 1960. Daí a ideia de sociedade urbana do autor como projeto e como processo, cuja concretização pressupõe a prevalência de necessidades sociais sobre interesses e prioridades do sistema econômico, de sorte que as condições de desigualdade que marcam as relações, entre centro e periferia, e que passaram a conformar a questão urbana ao fim do período industrial, possam ser superadas.

No dualismo centro e periferia, o centro é concebido como lócus de onde se projeta influência sociopolítica e econômica, constituindo parâmetro para a reprodução cultural. A capacidade de influência e o ambiente construído das áreas centrais favorecem a formação de meios de inovação, a partir da sinergia proporcionada pela concentração de elementos produtivos naquele espaço. A consequência disso é a caracterização da periferia como lugar daquilo que não exerce influência, isto é, espaço de residência dos mais pobres, de comunidades fragmentadas e incapazes de gerar capital social, de unidades fabris de baixa tecnologia, de serviços que requerem menor qualificação profissional e que têm menor rentabilidade. É devido a aspectos como esses que a contraposição centro e periferia revelou-se como divisão socioespacial, justamente porque essa divisão compreende amplas contradições classistas, sobretudo em países em desenvolvimento.

Hervé Marchal e Jean-Marc Stébé (2014, p. 117-139) problematizaram o conceito de centralidade na teoria lefebvriana, que relaciona a ideia de centralidades aos centros urbanos e que reafirma o dualismo centro e periferia. De acordo com os autores, a perspectiva de Lefebvre não se compatibiliza com o fato de que áreas periféricas também podem apresentar características que se identificariam com aquilo que Lefebvre entende como o "coração" da sociedade urbana, isto é, as regiões centrais, geralmente centros históricos e de ocupação tradicional.

Para alcançar suas conclusões, Marchal e Stébé trabalharam, na França, o conceito de áreas periurbanas, que são regiões equivalentes aos subúrbios ou às periferias de uma grande cidade; no entanto, a constatação de que a periurbanização, gerada pelo urban sprawl ou expansão urbana, foi acompanhada pelo aumento do número de centralidades invalidaria análises que se limitam à oposição binária entre centro e periferia. Daí a defesa da paradoxal concepção de "centralidades periféricas" como um aspecto da dinâmica urbana da atualidade, na medida em que elas apresentam ou têm o potencial de apresentar uma organização 
social autônoma em relação ao centro tradicional, a core city metropolitana, conjugando, pois, qualidades da cidade e do espaço não urbanizado.

Sem embargo, os autores relativizam suas próprias conclusões, ao afirmarem que a possibilidade de formação de "centralidades periféricas" não invalida, por completo, a ideia de centralidade apresentada por Lefebvre, considerando-se que a ausência de densidade urbana pode resultar, no caso concreto, em uma recuperação da relação binária centro e periferia. Essa relativização é importante para que se possa distinguir processos de periurbanização brasileiros daqueles que soem ocorrer em países desenvolvidos. Em outras palavras, os maiores níveis de desigualdade verificados, na relação centro e periferia, no Brasil, tendem a diminuir a densidade urbana em áreas periféricas ou periurbanas, inibindo o desenvolvimento de "centralidades concretas" em regiões não centrais, isto é, centralidades periféricas de alta densidade urbana. Não obstante, isso não significa defender que o dualismo centro e periferia deva necessariamente prevalecer como viés de análise para países em desenvolvimento.

\section{Desenvolvimento e organização espacial das atividades econômicas: competitividade e dependência na} relação centro-periferia

No atual estágio da evolução capitalista, a competitividade econômico-comercial está diretamente relacionada ao nível de dotação tecnológica e humana de cada localidade, refletindo aquilo que se convencionou chamar de "economia do conhecimento". Robert Gilpin (2002) observa que as novas teorias econômicas, como as teorias do crescimento e a nova geografia econômica, trouxeram contribuições fundamentais, especialmente por abordarem aspectos que foram, total ou parcialmente, negligenciados pelos economistas clássicos, como a ênfase em tecnologia e a importância das noções sobre tempo e espaço. Nesse contexto, vertentes teóricas desenvolvimentistas que basearam processos de modernização de tipo industrial, na segunda metade do último século, foram gradualmente superadas, como o estruturalismo e as teorias da dependência, responsáveis por realçarem o aspecto da dependência na interação entre centro e periferia no sistema internacional ${ }^{5}$.

A contribuição do institucionalismo econômico também tem significativa importância para a análise sobre o aspecto da dependência, na interação centro e periferia, bem como para as questões relativas ao desenvolvimento periférico. Da perspectiva institucionalista histórica, a importação de instituições formais,

\footnotetext{
${ }^{5}$ As políticas desenvolvimentistas ficariam conhecidas como aquelas que têm objetivos ambiciosos e expectativas de transformação do status quo em curto prazo (GOMIDES E PIRES, 2014); e o Estado desenvolvimentista, como o tipo de organização sociopolítica que pretende transformar rápida e permanentemente sua colocação no ranking global de países (SCHNEIDER, 2014). Embora as estratégias desenvolvimentistas do século XX auxiliem os atuais tomadores de decisão, elas não se mostram adequadas ao presente quadro da evolução capitalista, em especial devido às mudanças nas capacidades decisórias das administrações públicas, cada vez mais pressionadas pela necessidade de transparência e de controle social.
} 
por exemplo, evidencia uma atitude que não raramente se revela inócua, contraditória ou mesmo problemática por parte de elites nacionais, em face do significativo diferencial de condições e de circunstâncias históricas e sociais que acometem cada país em seus respectivos processos de desenvolvimento (CHANG, 2004). De outro lado, as novas teorias econômicas, como a "abordagem das capacidades", concebem importantes funções para a ação do Estado no processo de desenvolvimento econômico, contanto, sobretudo, que a atuação estatal esteja orientada para o acúmulo de tecnologia e de conhecimento (GILPIN, 2002, p. 193 et seq).

Mutatis mutandis, essas considerações fazem-nos refletir sobre o potencial de desenvolvimento das periferias urbanas, em face da dinâmica de desenvolvimento que baseia a interação desses espaços com áreas centrais. Em especial, o processo histórico de entendimento e de reação à situação periférica nacional, quanto aos países desenvolvidos, joga luzes sobre os desafios de engajamento social e de construção institucional voltados à adequada superação da questão periférica em grandes cidades brasileiras. A realidade das periferias intramunicipais insere-se nesse contexto de busca por mecanismos institucionais que possam, de um lado, auxiliar a reversão das condições de dependência e de vulnerabilidade social, que, no espaço urbano, se concentram precisamente nessas localidades; de outro, compensar falhas de mercado. Afinal, a assimetria das condições de vida, entre regiões centrais e periféricas de grandes cidades, revela não apenas sérias contradições classistas, mas também um processo de organização espacial significativamente desigual, que se caracteriza por uma complexa divisão técnica do espaço.

De acordo com Roberto Lobato Corrêa (2000, p. 28-46), a organização espacial das atividades socioeconômicas constitui o outro lado da produção do espaço, reproduzindo as características da sociedade que a gerou, como o modo de desenvolvimento das forças produtivas, a forma dominante das relações sociais, assim como as interações entre a própria sociedade e as instituições políticas formais existentes no território. A assimetria das condições sociais determina, por exemplo, a dinâmica de estabelecimento de centralidades urbanas; a dispersão ou a concentração espacial da indústria; o desenvolvimento de serviços de alto valor agregado ou do "circuito inferior da economia"; a instalação de órgãos públicos, centros universitários e de infraestrutura urbana; os assentamentos residenciais.

Um aspecto a ser destacado é a desigual atuação do capital sobre o espaço urbano, que reflete significativamente o diferencial das condições produtivas presentes na sociedade, sem deixar de incluir também as preferências pessoais dos próprios empresários. A existência de estruturas oligopolísticas, em importantes setores do mercado, tende a acentuar a socialização de custos privados derivados da atividade produtiva, o que tem significativas conexões com a problemática da renda fundiária urbana. Daí decorre, inclusive, a importância da ação estatal como forma de atenuar a organização espacial associada ao processo de acumulação capitalista; afinal, agentes privados não se encontram vinculados a necessidades de 
universalização do acesso aos benefícios e às comodidades da vida urbana. Apesar disso, o Estado, longe de ser neutro e à semelhança do capital, também atua desigualmente no espaço e, com frequência, de acordo com interesses prevalecentes da sociedade, agenciados por aqueles setores que dispõem de melhores condições de influência, conhecimento e de informação.

No que se refere à relação entre concentração e desconcentração produtiva, no contexto da organização do espaço urbano, o processo que ocorre, em nível regional e nacional, também é experimentado em nível local. Se, de um lado, a formação de "subcentros comerciais" ou de "centralidades periféricas", especialmente o circuito inferior da economia, vincula-se à evolução demográfica, de outro, ela está conectada às necessidades do próprio capital de operar uma desconcentração relativa, em que o capital excedente se rearticula em áreas periféricas que demonstram vantagens produtivas. Dificilmente, porém, antigos centros e centralidades dinâmicas deixam de constituir o núcleo da atividade produtiva, reafirmando, em outras bases, as relações de dependência entre centro e periferia. A incidência do setor informal, nas periferias, assim como do pequeno capital, também contribui para reproduzir um tipo de organização espacial que irá refletir, por sua vez, os principais determinantes de sua condição, em termos humanos, materiais e tecnológicos.

A reflexão crítica sobre a organização espacial das atividades econômicas, portanto, apresenta importância fundamental para a transformação da estrutura de desigualdades que tem marcado o processo de expansão das cidades, trazendo à luz o debate sobre a política e o planejamento urbano-territorial em grandes municípios.

\section{Empreendedorismo e o desenvolvimento urbano em grandes cidades}

As reformas do modelo produtivo e do próprio Estado, iniciadas em países desenvolvidos, a partir dos anos de 1970, repercutiram sobre as estratégias de desenvolvimento urbano que passaram a ser adotadas nas décadas seguintes. A passagem do administrativismo ao empreendedorismo (HARVEY, 2005) relaciona-se a essas mudanças, que tornaram o planejamento urbano ortodoxo, em grande medida, incompatível com o novo cenário.

Uma das características do processo flexível de acumulação capitalista foi a emergência das cidades como importantes atores no sistema capitalista internacional, à medida que os agentes locais, incluindo administrações municipais, assumem a condição de promotores do desenvolvimento urbano. A chamada "agenda local" reforça o empreendedorismo, apoiando-se em parcerias público-privadas como solução para restrições orçamentárias de entes locais. Nesse contexto, o ambiente construído é tido como um ativo para as instituições financeiras, que investem, desinvestem ou redirecionam capital para os usos mais lucrativos no 
ambiente construído. Trata-se de modelo, pois, que acentuou as assimetrias de competividade entre agentes econômicos, mas também entre localidades. A globalização financeira e o modelo de produção flexível reforçaram as relações entre a urbanização e o processo de acumulação capitalista, conferindo-Ihes escala planetária e, em consequência, uma instabilidade sistêmica, verificável na intensificação de crises financeiras associadas à atividade imobiliária6 (HARVEY, 2011).

Relativamente à questão das desigualdades socioespaciais, a ênfase conferida às estratégias de regeneração urbana tem acentuado a dualidade centro-periferia; afinal, o empreendedorismo tende a negligenciar as questões de fundo da problemática urbana, mediante sua relação com um tipo de planejamento, chamado estratégico, que operacionaliza a atuação das instituições públicas locais às condições tidas como ideais à inserção internacional competitiva, à atração de investimentos e, em última análise, à consolidação da política urbana (COMPANS, 2005). O foco empreendedorista na economia política do lugar, e não na do território, implica a ausência de prioridades quanto ao campo social nas ações de exploração econômica, que tendem a voltar-se aos chamados portfólios urbanos ou focos de interesse do capital produtivo e financeiro, como os centros comerciais e as unidades imobiliárias direcionadas às classes de média e de alta renda.

Reforma urbana e redemocratização: a instituição do novo ordenamento jurídico-urbanístico no país

A "urbanização da sociedade" (SANTOS, M., 1993), a rediscussão acadêmica sobre a questão urbana (LEFEBVRE, 1969; HARVEY, 1973; CASTELLS, 1974), bem como a crescente deterioração das condições de vida, nas cidades, ocasionaria uma nova atitude por parte da sociedade civil engajada, o que foi fundamental para revigorar a luta por uma reforma urbana, no Brasil, como reação ao conjunto de vulnerabilidades e de injustiças sociais, em meados dos anos de 1970. Proeminente no processo de redemocratização, o movimento pela reforma urbana destacou-se, de um lado, por vincular a reforma urbana ao ideário do direito à cidade, que apresenta caráter redistributivista e universalista em relação ao produto do espaço urbano; de outro, por defender um dispositivo constitucional que reconfigurasse o sistema de política e de planejamento urbanos, tornando-o capaz de viabilizar um enfrentamento direto ao tipo de urbanização prevalecente no país. Apesar do contrarreformismo de alguns setores sociais, o movimento foi determinante para conformar um ambiente institucional urbanístico inovador, decorrente da introdução do capítulo sobre política urbana na Constituição da República, que funcionalizou socialmente a propriedade urbana e a cidade.

\footnotetext{
6 O Brasil não escapou às dinâmicas do chamado processo de financeirização do espaço urbano, o qual impacta as estruturas socioeconômicas de maneira abrangente. Como evidência disso, consolidou-se, no país, um "complexo imobiliário-financeiro" (ROLNIK, 2015) que se mostra incapaz de reverter o histórico déficit de moradia popular. O expressivo impacto do liberalismo e do empreendedorismo na dinâmica das políticas urbanas implementadas, no país, não deve ser menosprezado, constituindo aspecto que responde por limitações ao programa jurídico-urbanístico constitucional.
} 
O Estatuto da Cidade, Lei federal n. 10.257/2001, ao regulamentar os artigos 182 e 183 constitucionais, consolidou as bases do ambiente institucional relativo às políticas urbanas no Brasil, tomando-se por ambiente institucional o conjunto de regras gerais que fundamentam o funcionamento dos sistemas político, econômico e social (GOMIDE E PIRES, 2014, p. 19) ${ }^{7}$. Como lei geral do urbanismo, no país, o ambiente institucional estabelecido pelo Estatuto da Cidade é complementado por outras leis e atos normativos, uma vez respeitadas as respectivas competências dos entes federados, não sendo demasiado reiterar que os municípios têm predominância de interesses quanto aos assuntos locais.

Não obstante, as expectativas positivas geradas pelos avanços jurídico-urbanísticos ocorridos desde a redemocratização têm sido revertidas por sentimento de crescente frustração, diante da significativa falta de efetividade e de eficácia (respectivamente, a não implementação e a não geração de resultados esperados) do quadro urbanístico institucional que foi consolidado, nas últimas três décadas, e com o qual se esperava fazer avançar a agenda da reforma urbana (MARICATO, 2011; CALDAS, 2015; SANTOS, A., 2017). Ainda que melhorias nas condições de vida das grandes cidades tenham sido verificadas (IPEA, 2017), de fato, o sentimento de frustração explica-se pela continuidade e, em alguns casos, até pelo agravamento da questão urbana brasileira, na medida em que, em termos estruturais, o sistema de política urbana não tem revertido as tendências de reprodução do paradigma da urbanização periférica.

Entre os fatores que contribuem para esse quadro de frustrações, além do impacto do empreendedorismo e de desafios técnicos e financeiros, muitos se referem a instituições e a padrões institucionalizados de comportamento da sociedade (NORTH, 1990; PERISSINOTTO, 2004). Nesse sentido, é preciso enfatizar a presença de uma tradição jurídica civilista, que dificulta a realização do potencial da função social da propriedade urbana (FERNANDES, 2006); do elitismo das classes hegemônicas, que esvazia as instâncias de democracia participativa e naturaliza, por meio de uma racionalidade de mercado, a ampla dimensão alcançada pela segregação socioespacial (SANTOS E AVRITZER, 2002); o anacronismo de uma ainda ampla perspectiva modernista sobre o Urbanismo, que inscreve as conformidades técnico-urbanísticas no referencial de eticidade da vida urbana (MAGALHÃES, 2013); as dificuldades de um modelo de federalismo marcado por insuficientes cooperação e coordenação intergovernamentais (SANTOS, A., 2017); e a continuidade de uma "gramática política brasileira", que, ao evidenciar uma transição capitalista incompleta pelo país, é responsável por preservar privilégios comumente confundidos com direitos meritocráticos e padrões de comportamentos que aumentam as possibilidades de corrupção urbanística, como o clientelismo, o corporativismo e o insulamento burocrático (NUNES, 2003; PRESTES, 2018).

\footnotetext{
${ }^{7}$ A Constituição, por exemplo, tornou complexa a implementação de políticas públicas, devido à ampliação dos instrumentos de transparência e de controle do setor público.
} 
Com efeito, esses aspectos impactam sobremaneira as possibilidades de efetividade e de eficácia de instrumentos urbanísticos, em particular aqueles que foram pensados como meio de induzir o desenvolvimento socioeconômico e de equilibrar as cidades. Inclusive por isso, a literatura relativa à temática urbana passou a ressaltar que a solução para a crise urbana é essencialmente política (MARICATO, 2013, p. 13-20; HARVEY, 2012).

A esse respeito, partindo do viés institucionalista, é oportuno lembrar que o êxito de políticas de desenvolvimento não pode ser relacionado apenas ao ambiente institucional a que elas se encontram vinculadas, sendo necessário viabilizar arranjos institucionais eficazes para esse fim também. Os arranjos institucionais consistem no "conjunto de regras, mecanismos e processos que definem a forma particular como se coordenam atores e interesses na implementação de uma política pública específica" (GOMIDE E PIRES, 2014, p. 19). Isto é, os arranjos institucionais definem a forma concreta por meio da qual as políticas públicas operam, uma vez referenciadas pelo ambiente institucional. Tais arranjos proporcionam o enfoque analítico acerca do processo de implementação de políticas públicas, evidenciando, no campo políticoadministrativo, as interações entre os agentes, as instituições e a burocracia estatal ${ }^{8}$.

Para Gomide e Pires (2014), as capacidades políticas, que pressupõem as interlocuções entre a burocracia estatal e a sociedade civil, têm a função de legitimar a atuação estatal em regimes democráticos, na medida em que rompem o insulamento da esfera administrativa, respondendo, de maneira significativa, pela possibilidade de eficácia das políticas públicas. Em verdade, a concepção de capacidades políticas, associada ao conceito de arranjos institucionais, sustenta a noção de que a maior abertura da burocracia estatal à participação e ao controle sociais auxiliam o processo de implementação de políticas públicas, sobretudo no que se refere à superação de problemas e à geração de inovações. Por exemplo, a pluralidade, nos processos decisórios, ampliaria a qualidade e a legitimidade das políticas públicas; o consenso acerca das ações a serem realizadas facilitaria a própria execução dessas ações, ao passo em que decisões tomadas sem o alcance desse consenso poderiam enfrentar, na fase executória, óbices significativos à sua eficiência e à sua eficácia.

Desenvolvimento periférico à luz do instrumental de política urbana do Estatuto da Cidade

\footnotetext{
8 Essas interações significam, em especial, a coordenação de interesses entre diferentes agentes, como ocorre no âmbito das contratações públicas ou mesmo das operações urbanas consorciadas. De acordo com essa perspectiva, os arranjos institucionais determinam a capacidade estatal de implementar políticas públicas; não obstante, essa capacidade, em regimes democráticos, pode ser: i. burocrática, no sentido weberiano, associada à dimensão técnico-administrativa; ii. política, que consiste no aspecto da negociação e da interlocução da burocracia com a sociedade civil.
} 
Diante da complexidade dos desafios de gestão e de governança urbanas, cumpre analisar o instrumental de política urbana da Lei federal n. 10.257/2001, a partir de uma perspectiva que considere o desenvolvimento socioeconômico das grandes periferias intramunicipais, sem ignorar um relevante aspecto caracterizador dos instrumentos urbanísticos brasileiros: no país, esses instrumentos foram estabelecidos para enfrentar "a posteriori um processo histórico-estrutural de segregação espacial" (FERREIRA, 2003, p. 06). Em seu art. 4으, que versa sobre os instrumentos de política urbana, o Estatuto da Cidade enumera instrumentos que têm especial relevância à análise sobre o desenvolvimento periférico, com base na atuação dos entes municipais. Tendo-se em vista os fins deste trabalho, serão analisados, a seguir, os instrumentos de política urbana relativos à operação urbana consorciada e à outorga onerosa do direito de construir.

\section{Operação Urbana Consorciada (OUC)}

Prevista, nos artigos 32, 33, 34 e 34-A, do Estatuto da Cidade, a OUC é definida como conjunto de intervenções e de medidas de caráter urbanístico que, coordenado pelo poder público, contará com a participação da sociedade no processo de sua formulação, execução e de seu controle, com o objetivo de alcançar transformações urbanísticas estruturais, melhorias sociais e valorização ambiental em determinada área da cidade ${ }^{9}$. Como a legislação estabelece a necessidade de determinar uma área específica do território municipal que será objeto da OUC, a parceria público-privada a ela associada irá compreender também a aprovação legislativa de um projeto urbano, em conformidade com o macroplanejamento municipal, no qual serão realizadas as intervenções que implicam o redesenho da área e os investimentos para sua execução, bem como o manejo de parâmetros urbanísticos.

Assim como ocorria com as operações urbanas integradas e interligadas, o principal mecanismo pensado para induzir o desenvolvimento da área que é objeto da OUC consiste na possibilidade de gozo de flexibilizações da legislação urbanística pelos agentes privados, flexibilizações que compreendem benefícios previstos no art. 32 da Lei n. 10.257/2001. A essa superveniência de uma regulação urbanística especial atribuise a capacidade de gerar a autossuficiência econômico-financeira das operações urbanas consorciadas, precisamente em razão das contrapartidas do setor privado, que devem ser aplicadas exclusivamente no próprio perímetro da operação.

\footnotetext{
9 Em verdade, sua própria denominação como operação urbana permite relacionar a OUC a experiências jurídico-políticas passadas, estrangeiras e nacionais; com efeito, estas vieram a ser suplantadas pela uniformização conceitual promovida pela Lei federal $n$. 10.257/2001, como foi o caso das operações urbanas interligadas e integradas do município de São Paulo. Já o ânimo quanto a essa forma de parceria deve ser compreendido, à luz do contexto de mudanças das estratégias de desenvolvimento urbano. Em particular, a consolidação de um instrumento como as operações urbanas, nos anos de 1980, respondia à carência de recursos públicos a serem revertidos para o campo da política urbana; ao avanço das concepções sobre controle do potencial construtivo pelo poder público e consequente captura da valorização imobiliária; e às limitações da antiga política de zoneamento.
} 
Apesar disso, o mecanismo de indução aos investidores privados tem-se revelado, na prática, insuficiente. Conforme a experiência com as operações urbanas integradas e interligadas demonstrou (MARICATO E FERREIRA, 2003; FIX, 2004), o pressuposto sistêmico para a atração de investimentos privados, para a área que é objeto desse instrumento de política urbana, é, sobretudo, a expectativa de mercado quanto à rentabilidade decorrente da exploração da área da operação. Essas expectativas estão significativamente conectadas à própria dinâmica do mercado imobiliário, cujo funcionamento independe, em grande medida, do impacto da regulação urbanística especial associada às operações urbanas. Assim sendo, o custo de oportunidade de investimentos realizados, em uma OUC que se encontre em uma periferia intramunicipal, pode simplesmente ser superior ao custo de oportunidade dos investimentos feitos em áreas centrais e em centralidades de alta densidade urbana.

Por esse motivo, inclusive, as operações urbanas, de acordo com Mariana Fix (2004, p. 05), tendem a concentrar-se onde existe interesse do mercado, como as áreas de expansão do mercado imobiliário. Essa observação evidencia que os cálculos de risco e de retorno que determinam o investimento privado representam óbice considerável para que o instrumento da OUC possa apresentar-se, com eficácia, nas grandes periferias intramunicipais.

Constatou-se, com a prática das operações urbanas, que a realidade da "gramática política brasileira" (NUNES, 2003) constitui obstáculo para que esse instrumento urbanístico seja, de fato, autossuficiente, do ponto de vista financeiro, e, mais do que isso, para que ele possa representar uma alternativa concreta de desenvolvimento periférico nas grandes cidades. Afinal, uma das justificativas apresentadas quanto a esse instrumento é o de que o aumento de inversões privadas, nos perímetros da OUC, ao tornar desnecessário o investimento público nestas áreas, habilitaria o poder público municipal a utilizar o excedente financeiro, daí derivado, em outras regiões da cidade. Não obstante, a pretensa autossuficiência da OUC deve ser questionada, mediante a evidência de que, com frequência, o poder público financia obras estruturantes nas áreas compreendidas pelas operações urbanas, tanto antes como após a aprovação do instrumento, como forma de tornar a própria operação mais atrativa ${ }^{10}$. Além disso, como pudemos analisar, a incapacidade estatal de assegurar contrapartidas do setor privado, por benefícios concedidos como estímulo às atividades privadas, marca a história do planejamento brasileiro, não devendo surpreender que a implementação da OUC, baseada em real contrapartida do setor privado, revele-se problemática em cidades brasileiras.

Os efeitos regressivos da concentração de recursos públicos e privados, nas áreas e no entorno de operações urbanas, devem ser ressaltados. As operações urbanas compreendem articulações institucionais

\footnotetext{
10 Mariana Fix (2004, p. 03) referiu-se a essas intervenções, financiadas com recursos públicos, como "âncoras" ou "projeto motor" das operações urbanas. Laisa E. M. Stroher (2017, p. 469) destaca que, na década de 1990, 85\% dos investimentos públicos voltados à infraestrutura urbana, no município de São Paulo, concentrou-se na própria área abrangida pelas operações Faria Lima e Água Espraiada ou em seu entorno imediato.".
} 
que colocam o poder público na posição de principal responsável pelos riscos da operação, o que pode ocorrer, ao menos, de duas formas. Em primeiro lugar, em decorrência do insucesso do projeto, a despeito de eventuais investimentos que o poder público tenha realizado, com recursos próprios, para estimular o investimento privado na área que é objeto da operação, incluindo prévia urbanificação. Em segundo, em razão de mecanismos financeiros associados à emissão de títulos mobiliários, de acordo com o previsto no art. 34 do Estatuto da Cidade. A emissão desses títulos, chamados certificados de potencial adicional de construção (CEPAC), foi pensado como meio de dinamizar as possibilidades de financiamento das operações urbanas, na medida em que amplia as possibilidades de negociação do potencial adicional construtivo e que os recursos provenientes da venda de CEPAC somente podem ser realizados na área objeto da operação.

As consequências da inserção da OUC no chamado complexo financeiro-imobiliário, contudo, não podem ser ignoradas. Na condição de título mobiliário, o CEPAC somente será exitoso, caso ele seja valorizável. A ausência de perspectiva de rentabilidade compromete a viabilidade do título, o que reforça o pressuposto sistêmico de funcionamento da OUC: a existência de interesse de investimento por parte do mercado, sem o qual não existirá parceria público-privada. A preocupação com a rentabilidade do CEPAC exacerba lógicas decorrentes da relação entre a esfera pública e a economia, como a constatação de que um elevado número de restrições normativas induz à fuga dos agentes privados ou à procura por brechas regulatórias (PINHEIRO E SADDI, 2005). O efeito disso, sobre o espaço urbano, tende a ser o relaxamento da legislação urbanística, em termos mais abrangentes do que os que foram planejados durante a elaboração do projeto da OUC. Ademais, o quadro de vulnerabilidade socioeconômica das periferias urbanas constitui elemento determinante da rentabilidade desses títulos mobiliários, uma vez que "a proximidade da população de baixa renda (leia-se, a maior parte da população) é talvez o maior fator de desvalorização imobiliária nas cidades brasileiras" (MARICATO E FERREIRA, 2002, p. 09). Por fim, há estímulo à socialização de custos, por meio de despesas públicas voltadas à valorização dos títulos mobiliários, especialmente à vista das conexões entre o uso especulativo desses certificados e as pressões agenciadas por setores mais influentes da sociedade. Não se deve ignorar também que as operações urbanas exigem ativa participação da máquina pública, que tende a ficar comprometida com operações realizadas em áreas valorizadas das cidades.

Nesse sentido, apontamos a existência de uma relação diretamente proporcional entre 1. os custos de oportunidade associados aos investimentos privados nas operações urbanas consorciadas e 2. a distância da área objeto da operação consorciada relativamente às regiões dotadas de maior dinamismo econômico ou que se constituem como vetores da expansão do mercado imobiliário. Essa constatação decorre da lógica de mercado em um sistema capitalista. Mesmo que esse sistema seja considerado em termos abstratos, a consequência dessa relação é o desestímulo, de natureza econômica, à ocorrência de operações urbanas consorciadas nas grandes periferias intramunicipais, sobretudo diante dos razoáveis limites, baseados no interesse social, que se devem impor ao manejo da legislação urbanística para a atração de investimentos. 
Não obstante, na sociedade brasileira, a relação diretamente proporcional apontada no parágrafo anterior tende a acentuar-se, quando se considera o padrão prevalecente de comportamento entre agentes públicos e privados, que se encontra marcado por práticas clientelistas e corporativistas e pelo insulamento da burocracia estatal. O padrão histórico de interações, entre as instituições políticas e a sociedade brasileira, especialmente o mercado, torna não apenas incerto, como improvável que o instrumental da OUC constitua alternativa viável de indução do desenvolvimento socioeconômico das periferias em grandes municípios.

Em alusão à teoria dos jogos da Economia, é improvável que agentes de mercado tenham como estratégia ótima o gozo dos incentivos existentes em OUCs realizadas nas periferias urbanas, se o padrão de interações, entre a sociedade civil e as instituições políticas do país, facilita, por meio da influência sobre o setor público, o gozo de benefícios semelhantes, mas com menores custos de oportunidade, em OUCs realizadas em regiões economicamente dinâmicas ou de expansão imobiliária. Nesse caso, portanto, a matriz de payoffs, isto é, o conjunto de opções, de benefícios e de recompensas dos jogadores, é claramente desfavorável à eficácia das operações urbanas consorciadas realizadas em grandes periferias intramunicipais. As fragilidades de marcos regulatórios, da atividade de controle da administração pública e das instâncias institucionais de participação social ampliam a capacidade de setores hegemônicos e com grande poder de mercado de fazerem valer seus interesses no processo de formulação e de execução de políticas públicas, sobretudo se considerarmos o pressuposto institucionalista de que os agentes privados são oportunistas na busca pela redução de custos transacionais ${ }^{11}$.

Em termos materiais, uma particularidade da sociedade brasileira, quanto ao uso de instrumentos baseados na parceria público-privada, como as operações urbanas, é o grau de vulnerabilidade socioeconômica que marca as periferias das grandes cidades, grau que não encontra paralelos entre países desenvolvidos que utilizam ou que utilizaram o tipo de estratégia de desenvolvimento urbano subjacente a essas operações. Em outras palavras: no que se refere à funcionalidade das instituições formais, a pobreza urbana pode ser significativamente distorciva. Assim sendo, as possibilidades de eficácia das OUCs, para o desenvolvimento das periferias intramunicipais em grandes municípios, precisa ser seriamente questionada, em face de uma dinâmica sistêmica e estrutural que tende a gerar a concentração de investimentos públicos e privados em áreas centrais ou em centralidades com significativo dinamismo econômico ou que se constituam como vetores de expansão do mercado, acarretando efeitos regressivos para as áreas periféricas ${ }^{12}$.

\footnotetext{
11 Esse quadro demonstra que as OUCs são aplicadas, no Brasil, em circunstâncias particularíssimas, que decorrem do processo de formação histórica do país. Naturalmente, as características marcantes da "gramática política" brasileira não ocorrem da mesma maneira, em todos os municípios, variando sua intensidade e sua complexidade, conforme variem aspectos locais como a localização regional, a rede de influências urbanas em que essas cidades se inserem, as dimensões territoriais e demográficas, assim como o processo interativo entre instituições formais e informais.

12 A análise que realizamos sobre OUCs atualmente em vigor, nos dois maiores municípios do país, corroboram essas conclusões (CRUZ, 2019).
} 


\section{Outorga Onerosa do Direito de Construir (OODC)}

À luz do desenvolvimento periférico, o que se pode dizer a respeito da OODC? Fundamentalmente, trata-se da capacidade que esse instrumento possui de contribuir com a regulação do mercado de terras urbanas e de redistribuir espacialmente recursos que são auferidos em decorrência de maiores aproveitamentos construtivos. Para esse fim, é necessário que o poder público seja efetivamente capaz de captar a mais-valia fundiária urbana. Nesse sentido, cumpre analisar a OODC, procurando compreender: 1. como esse instrumento pode contribuir com a regulação do mercado de terras urbanas, cuja valorização é grande responsável pela segregação socioespacial; 2. como a outorga onerosa pode ter eficácia em sua capacidade redistributiva.

Por certo, muitas das condições estruturais que acometem a OUC também impactam a OODC. Ambos os instrumentos, ao viabilizarem a flexibilização de parâmetros urbanísticos, desafiam, em particular, a eficácia do macroplanejamento urbano, tornando ainda mais complexa a ordenação das atividades e dos fluxos de investimentos nas cidades. Apesar disso, nas próximas páginas, será possível compreender importantes diferenças entre a OODC e a OUC, diferenças que determinam, de maneira significativa, possibilidades de eficácia da outorga onerosa para o desenvolvimento das periferias urbanas.

A OODC está prevista no art. 28 do Estatuto da Cidade, que autoriza o plano diretor a delimitar áreas em que o direito de construir poderá ser exercido acima do coeficiente de aproveitamento básico adotado no município, mediante contrapartida a ser prestada pelo beneficiário. As discussões a respeito da OODC remontam aos anos de 1970, quando se iniciou o debate sobre o instituto do solo criado, que, tendo intrínsecas relações com aquele instrumento, é admitido como "resultado de construção praticada em volume superior ao permitido nos limites do coeficiente único de aproveitamento" (GRAU, 1976, p. 136) ${ }^{13}$. Embora o Estatuto da Cidade tenha consolidado os fundamentos da OODC, pacificando grande parte das discussões a seu respeito, remanescem questionamentos sobre seu modo de implementação e sobre sua natureza jurídica, mesmo que o Supremo Tribunal Federal (BRASIL, 2008) tenha assentado o status do solo criado como ônus a ser suportado por proprietário de imóvel urbano ${ }^{14}$.

Em especial, o consenso doutrinário sobre a necessidade de estabelecer um coeficiente de aproveitamento básico único e igual a 1 (um) para o ideal funcionamento do instituto (GRAU, 1976; REZENDE et al, 2009) tem encontrado historicamente fortes oposições de setores da sociedade; por esse motivo,

\footnotetext{
${ }^{13} \mathrm{O}$ coeficiente único de aproveitamento deve ser entendido como a relação entre a área edificável e a área do terreno, sendo considerado, inclusive, consentâneo com referenciais de equidade social (GRAU, 1976).

14 As discussões acerca da definição, justificação e da experiência prática do solo criado ocuparam o último quartil do século passado, constituindo percurso histórico marcado por avanços e por retrocessos, seja em outros países, onde surgiram experiências muito influentes no Brasil (REZENDE et al, 2009), seja em municípios do país, notadamente em São Paulo, onde sua implantação tem sido proeminente.
} 
inclusive, a Lei federal n. 10.257/2001 não contemplou, in totum, a perspectiva sobre esse instituto que havia sido consagrada pela Carta de $\mathrm{Embu}^{15}$, em 1976, na medida em que o parágrafo 2o do art. 28 do Estatuto da Cidade também autoriza o poder público a estabelecer, no plano diretor, coeficientes diferenciados para áreas específicas da cidade, e não apenas uma densidade construtiva básica. Assim sendo, cada município está autorizado a estabelecer coeficientes de densidade construtiva, de acordo com as características de seu espaço imobiliário, estruturas de circulação e do nível de suas atividades socioeconômicas.

Considerando a existência de três tipos de coeficientes de aproveitamento, o mínimo, o básico e o máximo, é importante observar que o poder público somente está autorizado a manejar esses parâmetros, a partir do coeficiente básico, até os limites máximos e mínimos. Por sua vez, a captura da mais-valia deve ser entendida como o meio de remediar efeitos econômicos da atividade urbanística, em particular o zoneamento; afinal, da desigual estipulação de aproveitamentos construtivos, no território municipal, tendem a ocorrer desiguais valorizações imobiliárias, o que torna evidente a necessidade de um mecanismo que permita ao poder público recuperar o excedente econômico que beneficia certos proprietários fundiários, em detrimento de outros.

Na prática, a OODC consagrou o fato de que o potencial adicional de construção é de dominialidade pública, o que aumentou a capacidade estatal de intervir sobre o mercado imobiliário, corrigindo distorções do processo de urbanização e induzindo o desenvolvimento urbano, valendo-se das contrapartidas ao licenciamento imobiliário que intensifique o uso do solo em patamar superior aos parâmetros básicos. Com isso em mente, é possível apontar alguns dos principais pressupostos, não raramente disputados na sociedade, que afetam a dinâmica institucional correspondente à OODC e, em particular, sua eficácia para o desenvolvimento das grandes periferias intramunicipais: a) o objetivo estatal voltado ao adensamento de certas áreas urbanas; b) o interesse do setor privado no adensamento construtivo; c) a constatação de que o adensamento tende a valorizar o solo urbano; d) a exclusão e a segregação socioespaciais decorrentes da valorização imobiliária; e) os problemas de operacionalização do instrumento urbanístico, como a fórmula de cálculo da contrapartida; f) a real destinação dos recursos recuperados por meio do pagamento de contrapartida; g) a corrupção urbanística; h) as conjunturas de crise que diminuem o ritmo de licenciamentos imobiliários.

Em termos de recursos materiais, informacionais e políticos, os agentes periféricos não atuam em condições similares às dos agentes dominantes, relativamente ao processo de transformação urbana e de mudança institucional. Considerando-se que os coeficientes de aproveitamento construtivo têm valor de mercado, manifestado em uma relação diretamente proporcional, daí decorre que o aumento de densidades,

\footnotetext{
${ }^{15}$ A Carta de Embu foi o documento final de seminários, ocorridos no estado de São Paulo, em 1976, em que a concepção do solo criado foi enfaticamente defendida.
} 
no âmbito da política de solo, tende a constituir objetivo de muitos agentes do setor privado, sobretudo em uma sociedade com níveis de participação e de controle sociais de baixa intensidade. Ao lado das resistências à utilização de coeficientes de aproveitamento básico único, os coeficientes máximos também se tornam foco de pressões sociais no sentido de seu relaxamento, o que prejudica a possibilidade de a OODC constituir efetivo mecanismo de captação da mais-valia derivada dos processos de transformação urbana, na medida em que pode resultar em menor arrecadação pelo poder público.

Uma menor arrecadação derivada da outorga onerosa, por sua vez, compromete a dimensão da redistribuição espacial dos recursos levantados, ainda que sejam observadas as disposições do art. 26, incisos I a IX, e a ordem de prioridades de investimentos públicos democraticamente definida na cidade. De toda sorte, a desnecessidade de delimitação de perímetro para o reinvestimento derivado da OODC é realmente um fator muito importante, sob a perspectiva das periferias urbanas. Afinal, as tendências centralizadoras do mercado, que concentram as OUCs em áreas centrais ou vetores de expansão imobiliária, podem ser mais fortes, porque muito mais sistêmicas, do que o desvirtuamento da destinação final dos recursos no âmbito da OODC. É provável que o aumento do controle social, sobre o processo de redistribuição da mais-valia capturada pela outorga, seja de mais fácil consecução, em comparação com o caso das OUCs.

A eficácia de cada experiência local com a OODC não tem sido a mesma, na medida em que são muito amplos os desafios, inclusive técnicos, que obstaculizam a efetividade e a eficácia da outorga onerosa em cada município, notadamente o diferencial relativo aos padrões locais de interações entre as instituições políticas e a sociedade. Por exemplo, a nova regulamentação da OODC, em São Paulo, no contexto de revisão do Plano Diretor Estratégico paulistano (PDE) de 2014, implicou avanços notáveis em relação à implementação do instituto. O contraste dessa nova regulamentação não ocorre apenas quanto aos obstáculos institucionais que, do ponto de vista histórico, têm dificultado o formato de uma OODC defendido pela doutrina e por movimentos sociais, mas entre as capitais da região Sudeste do país também, uma vez que a atual experiência paulistana com um coeficiente de aproveitamento básico e único igual a 1 (um) era caso isolado até há pouquíssimo tempo ${ }^{16}$.

\footnotetext{
16 Foram firmadas uma nova fórmula de cálculo das contrapartidas à OODC, priorizando seus efeitos na organização territorial; uma estrutura de isenções e de incentivos mais razoável do que a até então prevista; a adequada noção do potencial construtivo adicional como bem jurídico dominical de titularidade da Prefeitura; e, em evidente contraste com os obstáculos sociopolíticos institucionais que historicamente comprometem o avanço da política urbana, firmou-se, como regra, a definição do coeficiente de aproveitamento básico e único igual a 1 (um) para todo o município, após sucessivas derrotas quanto a esse aspecto na história do planejamento urbano dessa cidade. No Rio de Janeiro, houve retrocesso quanto a à OODC, dada a comparação entre as disposições do atual plano diretor carioca, aprovado em 2011, e as disposições da legislação anterior - ainda que o então solo criado nunca tenha sido efetivamente aplicado. Em Vitória, em que pese a aprovação de novo plano diretor, em 2018, prevendo o uso da OODC, a regulamentação do instrumento ainda precisa ser realizada. Apenas Belo Horizonte passou também a dispor, mas apenas desde o segundo semestre de 2019, de plano diretor que regulamenta os principais fundamentos desse instituto urbanístico, incluindo a limitação a 1 (um) do coeficiente de aproveitamento básico em toda a cidade, após longo e extenuante processo de revisão do plano diretor local (CRUZ, 2019).
} 
A recente experiência paulistana com a implementação da OODC não há de ser considerada um modelo acabado, tendo-se em vista, sobretudo, as necessidades de aperfeiçoamento institucional e de atenção às específicas demandas do planejamento democrático. De toda maneira, se, de acordo com a doutrina, "uma conquista é sempre atingida quando um Plano Diretor institui a Outorga Onerosa do Direito de Construir" (CYMBALISTA E SANTORO, 2006, p. 23) e, sobretudo, se a OODC já tem tido importância $n^{17}$ a implementação dos Eixos de Estruturação da Transformação Urbana e destacadamente na composição do Fundo de Desenvolvimento Urbano (NOBRE, 2016), então é manifesto o logro paulistano com a regulamentação desse instrumento, em especial diante do aperfeiçoamento dos mecanismos de controle sobre a destinação dos recursos auferidos, destinação que não está territorialmente limitada, como ocorre com a OUC. Sobretudo em perspectiva comparada, a utilização desses recursos, em investimentos relativos à infraestrutura urbanísticosocial, começa a ter uma importante contribuição para o desenvolvimento periférico nesse município (CRUZ, 2019).

\section{CONSIDERAÇÕES FINAIS}

A solução política para o impasse da política urbana, no país, depende de uma efetiva reação à tradição civilista, no campo jurídico, que ainda obstaculiza a realização do potencial da função social da propriedade urbana; ao elitismo das classes hegemônicas, que esvazia a democracia participativa e naturaliza, por meio de uma racionalidade de mercado, a ampla dimensão alcançada pelos processos de exclusão e de segregação socioespaciais; à disseminação social de uma anacrônica perspectiva modernista que inscreve as conformidades técnico-urbanísticas no referencial de eticidade da vida urbana; e à continuidade de uma gramática política brasileira que, ao evidenciar uma transição capitalista incompleta pelo país, é responsável por preservar privilégios comumente confundidos com direitos meritocráticos, assim como padrões de comportamentos que aumentam as possibilidades de corrupção urbanística, como o clientelismo, o corporativismo e o insulamento burocrático.

Esses aspectos impactam sobremaneira as possibilidades de eficácia de instrumentos urbanísticos, em particular aqueles que foram pensados como meio de induzir o desenvolvimento socioeconômico e de equilibrar as cidades, como sugere a análise acerca das operações urbanas consorciadas e da outorga onerosa do direito de construir. Sem embargo, foi possível verificar que o impacto desses aspectos institucionais é exacerbado pela falta de competitividade estrutural das periferias urbanas, relativamente à atração de

\footnotetext{
17 Também não se deve negligenciar o fato de que a aprovação do PDE, em 2014, ocorreu com base em concessões políticas que implicaram mudanças importantes no projeto revisor original, impactando iniciativas como a Cota de Solidariedade e a própria OODC
} 
investimentos privados, sobretudo em razão da predominância de forças centralizadoras de riqueza em um sistema econômico capitalista.

Da análise realizada, verificou-se que a utilização de certificados de potencial adicional de construção reforça o pressuposto sistêmico de funcionamento das operações urbanas consorciadas, que é a existência de interesse de investimento por parte do mercado, sem o qual não existirá parceria público-privada. Isso significa, na prática, a concentração das operações, em áreas dotadas de maior dinamismo econômico relativo ou que se constituam como vetores de expansão do mercado imobiliário. Na medida em que o poder público tem agido significativamente, no espaço urbano, como agente especulador, a obrigatoriedade de utilização das contrapartidas privadas, no perímetro que é objeto das operações urbanas consorciadas, apresenta um caráter regressivo, à luz das necessidades de desenvolvimento das grandes periferias intramunicipais. Devido a isso, inclusive, é possível atribuir ao instrumento da outorga onerosa do direito de construir uma capacidade redistributiva não somente maior, mas também capaz de induzir investimentos diretos em áreas periféricas das grandes cidades. Em termos comparados, a outorga onerosa do direito de construir revela maior aplicabilidade espacial do que as operações urbanas consorciadas, o que tende a aumentar as possibilidades de eficácia das outorgas onerosas no território.

Em quase vinte anos, desde que prevista pelo Estatuto da Cidade, a operação urbana consorciada ainda não foi utilizada como instrumento de indução direta de desenvolvimento urbano periférico. No contexto sociopolítico e econômico em que têm sido utilizadas, as operações urbanas consorciadas apresentam-se funcionais apenas para áreas que correspondem a seu pressuposto sistêmico de funcionamento; assim sendo, é preciso situar esse instrumento de política urbana como mecanismo de indução de investimentos para áreas não periféricas das grandes cidades, afastando uma compreensão errônea segundo a qual, da utilização dos instrumentos de política urbana do Estatuto da Cidade, decorrem necessariamente benefícios para toda a cidade. Por certo, existem índices alarmantes de pobreza, fora das grandes periferias intramunicipais, isto é, em áreas onde a operação urbana consorciada apresenta-se viável e ajudar a reverter, em alguma medida, índices absolutos de vulnerabilidade social; não obstante, os efeitos regressivos da utilização desse instrumento contribuem para a reprodução do paradigma da urbanização periférica em grandes cidades que ainda se expandem horizontalmente.

Apesar disso, haja vista que o poder público, ao se valer das operações urbanas consorciadas, não está obrigado a exigir contrapartida, em forma financeira, nem a utilizar a outorga de direito adicional de construção como mecanismo de atração de investimentos privados, é possível vislumbrar usos alternativos para esse instrumento de política urbana, sobretudo em contexto de concretização do controle social no processo de planejamento, formulação e de execução da operação urbana consorciada. 
Nesse sentido, podem ser considerados como desafios remanescentes comuns da utilização das operações consorciadas e das outorgas onerosas do direito de construir: efetivos mecanismos de participação e de controle social; ampliação de desenhos institucionais que gerem maior redistribuição espacial da captação de mais-valias; a projeção da periferia como efetiva categoria de análise e de referência no processo de revigoramento da democracia participativa e do exercício das capacidades políticas em arranjos institucionais. Especificamente quanto à utilização da operação urbana consorciada, remanesce o desafio de instituir uma regulação alternativa que, não descaracterizando o instrumento como outorga onerosa do direito de construir, viabilize um uso não regressivo à luz das necessidades de desenvolvimento periférico.

\section{REFERÊNCIAS}

BECKER, Bertha K.; EGLER, Claudio A. G. Brasil: Uma nova potência regional na economia do mundo. Rio de Janeiro: Bertrand Brasil, 1993.

BRASIL. Supremo Tribunal Federal. RE 387.047. Rel. Min. Eros Grau. Plenário. Diário Oficial da União. Brasília, 06 mar. 2008.

CALDAS, Maria Fernandes. Política urbana, ação governamental e a utopia da reforma urbana no Brasil [manuscrito] / Maria Fernandes Caldas. Belo Horizonte: UFMG, 2015.

CASTELLS, Manuel. A Questão Urbana. Rio de Janeiro: Paz e Terra, 1983.

CHANG, Ha-Joon. Chutando a escada: a estratégia do desenvolvimento em perspectiva histórica. São Paulo: UNESP, 2004.

COMPANS, Rose. Empreendedorismo urbano: entre o discurso e a prática. São Paulo: Editora UNESP, 2005.

CORRÊA, Roberto Lobato. Região e organização espacial. São Paulo: Ática, 2000.

CRUZ, Carlos Eduardo de Souza. Desenvolvimento e Periferia: análise sobre possibilidades de eficácia de instrumentos de política urbana em periferias intramunicipais. [manuscrito] / Carlos Eduardo de Souza Cruz. Rio de Janeiro: UERJ, 2019.

CYMBALISTA, Renato; SANTORO, Paula F. Outorga Onerosa do Direito de Construir: entre a regulação e a arrecadação. Seminário Política fundiária Municipal e gestão social da valorização da terra. Anais. São Paulo, Instituto Pólis/Fundação Getúlio Vargas, 2006, $26 p$.

FERREIRA, João Sette Whitaker. Alcances e limitações dos Instrumentos Urbanísticos na construção de cidades democráticas e socialmente justas. Va Conferência das Cidades, Câmara Federal, 2003.

FIX, Mariana. A "fórmula mágica" da parceria público-privada: operações urbanas em São Paulo. Urbanismo: dossiê São Paulo-Rio de Janeiro. Campinas, PUCCAMP/PROURB, 2004, p. 185-198.

GILPIN, Robert. The political economy of International Relations. Princeton: Princeton University Press, 2016.

GOMIDE, Alexandre de Ávila; PIRES, Roberto Rocha C. Capacidade estatais e democracia: a abordagem dos arranjos institucionais para análise de políticas públicas. In: Alexandre de Ávila Gomide; Roberto Rocha C. Pires (ed.). Capacidade estatais e democracia: arranjos institucionais de políticas públicas. Brasília: IPEA, 2014, p. 15-31.

GRAU, Eros Roberto. Aspectos jurídicos da noção de solo criado. In: Fundação Prefeito Faria Lima - CEPAM. Solo Criado/Carta do Embu: anais do Seminário "O Solo Criado", 1976, pp. 134- 154.

HALL, Peter. Cities of Tomorrow. Nova Jérsei: Wiley Black-well, 2014.

HARVEY, David. A Produção Capitalista do Espaço. São Paulo: Annablume, 2005.

HARVEY, David. O enigma do capital: e as crises do capitalismo. São Paulo: Boitempo, 2011.

HARVEY, David. Rebel cities: from the right to the city to the urban revolution. London: Verso, 2012.

HOLSTON, James. Cidadania insurgente: disjunções da democracia e da modernidade no Brasil. São Paulo: Companhia das Letras, 2013.

IPEA. Atlas da Vulnerabilidade Social. 2017. Disponível em: <http://ivs.ipea.gov.br/index.php/pt/sobre>. Acesso em: 12 jun. de 2019. 
LEFEBVRE, Henri. O direito à cidade. São Paulo: Documentos, 1969.

LEFEBVRE, Henri. A Revolução Urbana. Belo Horizonte: Editora UFMG, 1999.

LIMA NETO, V. C., KRAUSE, C. H., BALBIM, R. N. Instrumentos urbanísticos à luz dos planos diretores: uma análise a partir de um circuito completo de intervenção. Brasília: Instituto de Pesquisa Econômica Aplicada, 2014.

LOJKINE, Jean. O Estado Capitalista e a Questão Urbana. São Paulo: Martins Fontes, 1981.

MAGALHÃES, Alex. O Direito das Favelas. Rio de Janeiro: Letra Capital, 2013.

MARCHAL, Hervé; STÉBÉ, Jean-Marc. From the city to crumbling urbanism: Beyond centre/periphery dualism. A re-Examination of Henri Lefebvre's concept of centrality. In: Gülçin Erdi-Lelandais (org.). Understanding the city: Henri Lefebvre and Urban Studies. New Castle: Cambridge Scholars Publishing, 2014, pp. 117-139.

MARICATO, Ermínia. Metrópole na periferia do capitalismo: ilegalidade, desigualdade e violência. São Paulo: Hucitec, 1996.

MARICATO, Ermínia. É a questão urbana, estúpido! In: David Harvey; Ermínia Maricato et al. Cidades rebeldes: Passe Livre e as manifestações que tomaram as ruas do Brasil. São Paulo: Boitempo, 2013, pp. 13-20.

MARICATO, Ermínia. O Impasse da política urbana no Brasil. Petrópolis: Vozes, 2014.

MARICATO, Ermínia; FERREIRA, João Sette Whitaker. Operação Urbana Consorciada: diversificação urbanística participativa ou aprofundamento da desigualdade? In: Letícia Marques Osório (org.). Estatuto da Cidade e reforma urbana: novas perspectivas para as cidades brasileiras. Porto Alegre: Sergio Antonio Fabris Editor, 2002.

MONTE-MÓR, Roberto Luís. O que é o urbano? 2006. Disponível em: <http://www.cedeplar.ufmg.br/pesquisas/td/TD\%20281.pdf>. Acesso em: 06 jun. 2019.

NOBRE, Eduardo A. C. Recuperação da valorização imobiliária para financiamento da transformação urbana. In: Eixos de Estruturação da Transformação Urbana: inovação e avaliação em São Paulo. Brasília: IPEA, 2016, pp.161-215.

NORTH, Douglas C. Institutions, institutional change and economic performance. Cambridge: Press Syndicate of the University of Cambridge, 1990.

NUNES, Edson. A gramática política no Brasil: clientelismo e insulamento burocrático. Rio de Janeiro: Jorge Zahar, 2003.

PERISSINOTTO, Renato Monseff. Política e sociedade: por uma volta à sociologia política. Florianópolis: Política \& Sociedade: Revista de sociologia política, v. 3, n. 5, 2004, p: 203-232.

PINHEIRO, Armando Castelar; SADDI, Jairo. Direito, Economia e Mercados. Rio de Janeiro: Elsevier, 2005.

PRESTES, Vanesca Buzelato. Corrupção urbanística: da ausência de diferenciação entre Direito e Política no Brasil. Belo Horizonte: Fórum, 2018, pp. 145-182.

REZENDE, V. F., FURTADO, F., OLIVEIRA, M. T. C., JORGENSEN JR., P. A outorga onerosa do direito de construir e o solo criado: uma necessária avaliação das matrizes conceituais. Revista Brasileira de Estudos Urbanos e Regionais, v. 11, n. 2, 2009, pp. 51-71

ROLNIK, Raquel. Guerra dos lugares: a colonização da terra e da moradia na era das finanças. São Paulo: Boitempo, 2015.

SANTOS, Angela Moulin Simões Penalva. Política urbana no contexto federativo brasileiro: aspectos institucionais e financeiros. Rio de Janeiro: EdUERJ, 2017.

SANTOS, A. P.; POLIDORI, M. C.; PERES, O. M.; SARAIVA, M. V. O Lugar dos Pobres nas Cidades: explorações teóricas sobre a integração da periferização e pobreza na produção do espaço urbano. Revista Brasileira de Gestão Urbana, set/dez 2017. Disponível em: <http://www.scielo.br/pdf/urbe/v9n3/2175-3369-urbe-2175-3369009003A004.pdf>. Acesso em: 20 jan. 2019.

SANTOS, Boaventura de Sousa; AVRITZER, Leonardo. Para ampliar o cânone democrático. In: Boaventura de Sousa Santos (org.). Democratizar a democracia: os caminhos da democracia participativa. Rio de Janeiro: Civilização Brasileira, 2002, pp. $39-82$.

SANTOS, Milton. A Urbanização Brasileira. São Paulo: Hucitec, 1993.

SCHNEIDER, Ben R. O Estado desenvolvimentista no Brasil: perspectivas históricas e comparadas. In: Alexandre de Ávila Gomide; Roberto Rocha C. Pires (ed.). Capacidades estatais e democracia: arranjos institucionais de políticas públicas. Brasília: IPEA, 2014, pp. 31-56.

STROHER, Laisa Eleonora Maróstica. Operações urbanas consorciadas com Cepac: uma face da constituição do complexo imobiliário-financeiro no Brasil? Caderno da Metrópole, São Paulo, v. 19, n. 39, pp. 455-477, maio/ago 2017.

VILLAÇA, Flávio. Uma contribuição para a história do planejamento urbano no Brasil. In: Csaba Deák; Sueli Ramos Schiffer (org.). $O$ processo de urbanização no Brasil. São Paulo: USP, 2004, pp. 171-243. 